American Journal of Applied Sciences 8 (1): 50-54, 2011

ISSN 1546-9239

(C) 2010 Science Publications

\title{
The Effect of a Prophylactic Dose of Ibuprofen on Plasma Level of Interleukin 1, Interleukin 6 and Tumor Necrosis Factor-Alpha in a 1500 m Running Practice
}

\author{
${ }^{1}$ Gholamreza Sepehri, ${ }^{2}$ Mohammad Pourranjbar, \\ ${ }^{3}$ Ghollam-Reza Moshtaghi-Kashanian, \\ ${ }^{3}$ Ali Siahposht Khachaki and ${ }^{4}$ Ehsan Sepehri \\ ${ }^{1}$ Neuroscience Research Center, Department of Physiology and Pharmacology, \\ ${ }^{2}$ Department of Physical Education, \\ ${ }^{3}$ Physiology Research Center, Department of Physiology and Pharmacology, \\ Kerman University of Medical Sciences, Kerman, Iran \\ ${ }^{4}$ Medical School, Tehran University of Medical Sciences, Tehran, Iran
}

\begin{abstract}
Problem statement: there are controversies about the effects of anti-inflammatory drugs on exercised induced changes on plasma cytokines in untrained male athletes, so the primary purpose of this study was to measure the influence of a prophylactic dose of ibuprofen use on plasma cytokines during a $1500 \mathrm{~m}$ running race. Approach: Subjects were 10 untrained male Medical University students who consumed $400 \mathrm{mg}$ ibuprofen two hours before the $1500 \mathrm{~m}$ running practice and 10 controls that competed in the race but avoided ibuprofen and all other medications. Blood samples were collected before, $1 \mathrm{~h}$ and $24 \mathrm{~h}$ following the $1500 \mathrm{~m}$ exercise bout to measure plasma concentrations of interleukin-1 beta (IL-1 $\beta$ ), interleukin-6(IL-6) and tumor necrosis factor alpha (TNF$\alpha)$. Results: There were not any significant differences between plasma concentration of IL-1 $\beta$, IL-6 and TNF- $\alpha$ during the study period. Also the data showed that there were not any significant differences between plasma level of IL-1 $\beta$, IL-6 and TNF- $\alpha$ in ibuprofen and control group during the study period. Conclusions/Recommendation: Our result showed that a prophylactic dose of ibuprofen did not affect acute inflammatory cytokines levels (IL-1 $\beta$, IL-6 and TNF- $\alpha$ ) in untrained healthy young males. So the etiology of the muscle soreness in athletes actively participating in sport races seems to be independent of inflammatory processes.
\end{abstract}

Key words: Plasma cytokines, Ibuprofen, Running race, strenuous exercise, Tumor Necrosis Factor Alpha (TNF- $\alpha$ ), Delayed-Onset Muscle Soreness (DOMS), C-Reactive Protein (CRP), Enzyme-Linked Immunosorbent Assay (ELISA), Non-Steroidal Anti-Inflammatory Drugs (NSAIDs), inflammatory cytokines

\section{INTRODUCTION}

It has been documented that strenuous exercise not only induces pyrogenesis but also elicits mobilization and functional augmentation of neutrophils and monocytes whereas it suppresses cellular immunity leading to increased susceptibility to infections (Shephard et al., 1994). It has been documented that exhausting en- durance exercise suppresses circulating lymphocyte count and cellular immune functions (Shephard et al., 1994; Pedersen and Bruunsgaard, 1995; Lopez et al., 1983; Trinchieri, 1989).

Stress may increase the production of Tumor Necrosis Factor Alpha (TNF- $\alpha$ ) through the production of norepinephrine (Gomez-Flores et al., 2005). Tumor Necrosis Factor Alpha (TNF- $\alpha$ ) level was significantly higher in a heavy-exercise in healthy young men performed bicycle ergometer exercises. The concentration of interleukin-1 alpha (IL-1 alpha) peaked at the early stage of the incremental exercise (Kimura et al., 2001). Also data demonstrate that water polo practice in adolescent girls leads to profound increases in inflammatory cytokines. Significant increases where noted in circulating interleukin-6 (IL-6) and interestingly, TNF- $\alpha$ level decreased after the exercise. Also water polo practice caused reductions in anabolic mediators with substantial alterations in white

Corresponding Author: Gholamreza Sepehri, Department of Physiology and Pharmacology, Kerman University of Medical Sciences, Kerman, Iran Tel: +98- 3413220081 Fax: +98- 341- 3220081 
blood cell subpopulations and adhesion molecules (Kimura et al., 2001; Nemet et al., 2003).

The increase in plasma cytokine levels has been reported in athletes competing in marathons and ultramarathons, long term bicycle exercise and athletes actively participating in sport races (Nieman, 1998; Ostrowski et al., 2000; Suzuki et al., 2002).

Collectively, these observations indicate that exercise increases the numbers of circulating cells positive for both pro/anti-inflammatory and growth factors, perhaps contributing to the organism's ability to effectively respond to a variety of post-exercise challenges, such as tissue injury and adaptation (Zaldivar et al., 2006).

The effect of anti-inflammatory drugs in the prevention of muscle soreness and inflammatory responses is reported by investigators. Semark et al. (1999) reported that a prophylactic dose of flurbiprofen did not affect Delayed-Onset Muscle Soreness (DOMS), muscle soreness in trained subjects (Semark et al., 1999). However, Kokkinidis et al reported that ibuprofen decreased muscle soreness induced after eccentric exercise (Tokmakidis et al., 2003). However, Nieman et al. (2006) reported that ibuprofen use compared to nonuse by athletes competing in a $160 \mathrm{~km}$ race did not alter muscle damage or soreness but decreased inflammatory cytokines (Nieman et al., 2006). Also Feng et al. ( 2000) reported that short-term aspirin therapy $(81$ or $325 \mathrm{mg} / \mathrm{d} / 7$ days $)$ in healthy male subjects doing strenuous exercise had no significant effect on C-Reactive Protein (CRP) level and suggest that aspirin may not affect the levels of inflammatory markers (Feng et al., 2000).

Since there are controversies about the effects of anti-inflammatory drugs on exercised induced changes on plasma cytokines in untrained male athletes, so the primary purpose of this study was to measure the influence of a prophylactic dose of ibuprofen use on plasma cytokines during a $1500 \mathrm{~m}$ running race.

\section{METERIALS AND METHODS}

Subjects were 23 untrained male Medical University students between the ages of 18 and 21 years whose characteristics were as follows (mean $\pm \mathrm{SEM}$ ): height $163.1 \pm 4.0 \mathrm{~cm}$, body mass $58.6 \pm 3.8 \mathrm{~kg}$. They met the following selection criteria ascertained using a written questionnaire. They were non-smokers, physically healthy and had no history of recent infection or other significant health disorders. They had taken no anti-inflammatory drugs and/or medications within at least 1 week prior to the study. None of the subjects had been involved in training activities. The
Ethics Committee of the Kerman University of Medical Sciences approved the experiment procedures $(\mathrm{K} / 88 / 53)$ and informed consent was obtained from the subjects.

Since the peak plasma level of Ibuprofen is reached after $1-2 \mathrm{~h}$, so 12 healthy volunteers received $400 \mathrm{mg}$ ibuprofen two hour before the starting of the $1500 \mathrm{~m}$ running race (Davies, 1998). Control group $(\mathrm{n}=11)$ received placebo.

Blood sampling: Approximately $5 \mathrm{~mL}$ peripheral blood was collected from an antecubital vein using a disposable needle and vacutainer containing heparin. Peripheral venous blood was drawn immediately before (Pre) and $1 \mathrm{~h}$ and $24 \mathrm{~h}(1 \mathrm{~d})$ after the $1500 \mathrm{~m}$ running race from all the athletes in ibuprofen and control groups (Hirose et al., 2004). The blood was centrifuged for $10 \mathrm{~min}$ to separate plasma. The samples were stored at $-70^{\circ} \mathrm{C}$ until analyses of inflammatory mediators; IL$1 \beta$, IL-6 and TNF- $\alpha$.

Cytokine assays: The heparin plasma samples were used for cytokine determination, which was performed with commercially available Enzyme-Linked Immunosorbent Assay (ELISA) kits (Bender MedSystems, Austria, Europe) according to the manufacturers' instructions. They were carefully checked for specificity, sensitivity and reliability. Plasma concentrations of IL- $1 b$, IL- 6 and TNF- $\alpha$ were measured using a series of ELISA kits.

Statistical analysis: Data are expressed as means \pm SEM. Changes from pre-race to post-race values were calculated and compared between ibuprofen and control groups using student's $t$ tests. The difference between groups was determined by analysis of variance (ANOVA), followed by the Tukey's post hoc test with $5 \%$ level of significance $(\mathrm{p}<0.05)$.

\section{RESULTS}

Plasma level of cytokines in control group: Figure 1 shows the plasma concentration of TNF- $\alpha$, IL- 6 and IL-1 $\beta$ in control group before (Pre), $1 \mathrm{~h}$ and $24 \mathrm{~h}$ (1d) after the $1500 \mathrm{~m}$ running race. As the data shows, there were not any significant differences between plasma concentration of IL-1 $\beta$, IL- 6 and TNF- $\alpha$ during the study period (Fig.1).

Plasma level of cytokines in Ibuprofen group: Figure 2 shows the plasma concentration of TNF- $\alpha$, IL6 and IL-1 $\beta$ in ibuprofen group before (Pre), $1 \mathrm{~h}$ and 24 $\mathrm{h}$ (1d) after the $1500 \mathrm{~m}$ running race. As the data shows, there were not any significant differences between plasma concentration of TNF- $\alpha$, IL- 6 and IL$1 \beta$ during the study period (Fig. 2). 


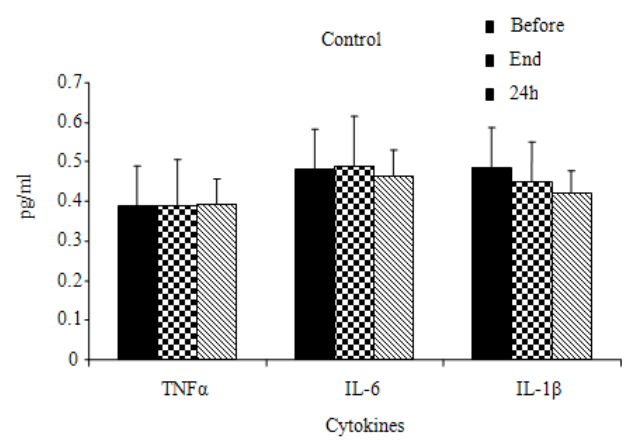

Fig. 1: Effects of exercise on plasma levels of TNF- $\alpha$, IL-6 and IL-1 $\beta$ before and after the $1500 \mathrm{~m}$ running practice. Values are means \pm SEM, $n=11$

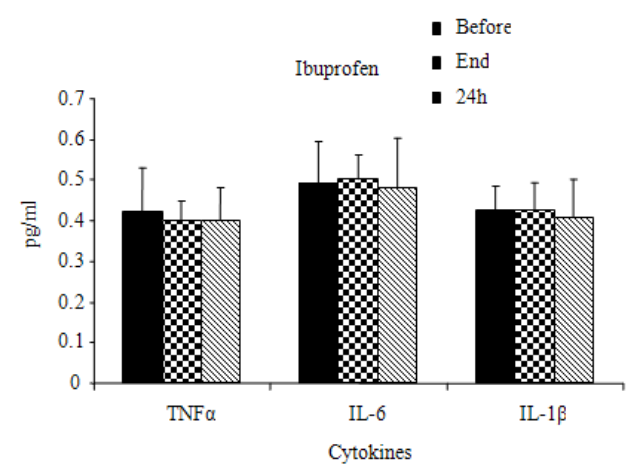

Fig. 2: Plasma cytokines level (TNF- $\alpha$, IL-6 and IL$1 \beta$ ) in ibuprofen users before and after the 1500 $\mathrm{m}$ running practice. Data are mean $\pm \mathrm{SEM}, \mathrm{n}=12$

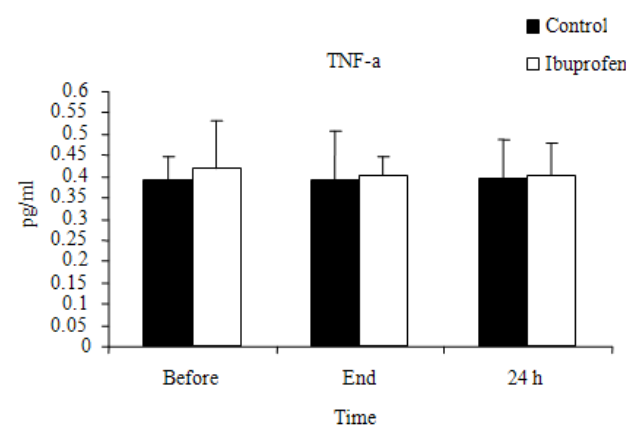

Fig. 3: Effects of exercise on plasma levels of TNF- $\alpha$ before and after the $1500 \mathrm{~m}$ running practice. Values are means \pm SEM of 11 samples in control and 12 samples in Ibuprofen group

Also the data showed that there were not any significant differences between plasma level of TNF- $\alpha$, IL-6 and IL-1 $\beta$ in ibuprofen and control group during the study period (Fig. 3-5).

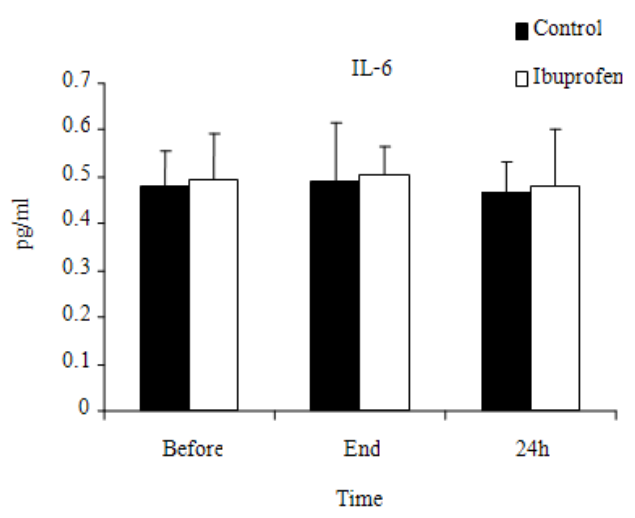

Fig. 4: Effects of exercise on plasma levels of IL-6 before and after the $1500 \mathrm{~m}$ running practice. Values are means \pm SEM of 11 samples in control and 12 samples in Ibuprofen group

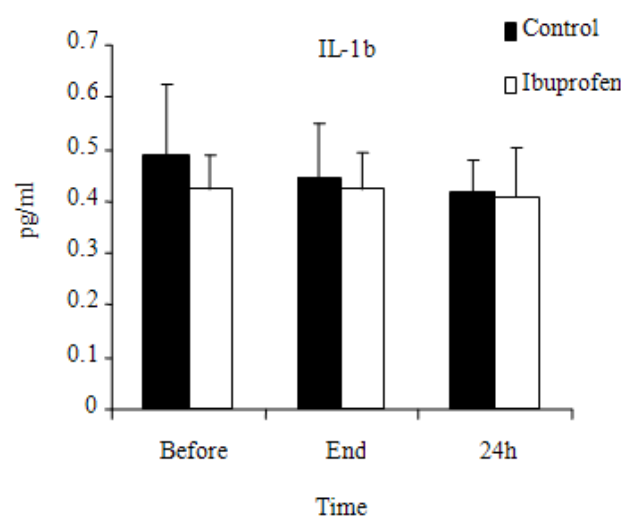

Fig. 5: Effects of exercise on plasma levels of IL-1 $\beta$ before and after the $1500 \mathrm{~m}$ running practice. Values are means \pm SEM of 11 samples in controland 12 samples in Ibuprofen group

\section{DISCUSSION}

The results of this study showed that there were no significant differences between the plasma cytokine (TNF- $\alpha$, IL-6 and IL-1 $\beta$ ) levels at pre and post $1500 \mathrm{~m}$ running race in untrained healthy young males. Our results are comparable to Suzuki et al. (2002) study who reported that the circulating concentration of these cytokines is either unchanged following exercise, or exhibits relatively small, delayed increments (Suzuki et al., 2002). However, our results are not comparable to some other studies in which the increase in acute inflammatory cytokines levels such as IL-1 $\alpha$ and TNF- $\alpha$ has been reported in athletes competing in marathons and ultramarathons, long term bicycle exercise and athletes actively 
participating in sport races (Nieman, 1998; Ostrowski et al., 2000; Suzuki et al., 2002; Nemet et al., 2002). However, others reported the decrease in tumor TNF$\alpha$ level after the exercise (Nemet et al., 2003).

Also our result showed that a prophylactic dose of ibuprofen did not affect acute inflammatory cytokines levels (IL-1 $\beta$, IL- 6 and TNF- $\alpha$ ) in untrained healthy young males. Our results are not comparable to Nieman et al. (2006) study which showed that ibuprofen use compared to nonuse was linked to a greater increases (pre-to-post race) in serum C-Reactive Protein (CRP) and plasma cytokine levels for interleukin (IL)-6, IL10, IL-8, IL-1 ra, but not tumor necrosis factor alpha (Nieman et al., 2006). However Feng et al. (2000) reported that in healthy male subjects CRP levels were not significantly reduced by short-term aspirin therapy. Also the effect of a prophylactic dose of Non-Steroidal Anti-Inflammatory Drugs (NSAIDs) on muscle damage or soreness is controversial. Tokmakidis et al. (2003) reported that ibuprofen use compared to nonuse by athletes can decrease muscle soreness induced after eccentric exercise which is not comparable to the results of some other similar studies (Suzuki et al., 20002; Semark et al., 1999; Nieman et al., 2006). Since ibuprofen did not affect the inflammatory cytokines in untrained athletes, so the etiology of athletes muscle soreness seems to be independent of increases in prostaglandin (Semark et al., 1999).

\section{CONCLUSION}

The results of this study showed that a prophylactic dose of ibuprofen did not affect acute inflammatory cytokines levels (IL-1 $\beta$, IL- 6 and TNF- $\alpha$ ) in untrained healthy young males. So the etiology of the muscle soreness in athletes actively participating in sport races seems to be independent of inflammatory processes. Our data, taking together with other reports, suggest that ibuprofen may not affect the levels of inflammatory cytokines levels. However, further studies are needed with a longer duration of therapy, among trained and untrained athletes and using additional markers of inflammation besides IL- $1 \beta$, IL6 and TNF- $\alpha$ to determine the short and long-term effects of ibuprofen use.

\section{ACKNOWLEDGMENT}

This publication was funded by Physiology Research Center, Kerman University of Medical Sciences, Kerman, Iran.

\section{REFERENCES}

Davies, N.M., 1998. Clinical pharmacokinetics of ibuprofen: The first 30 years. Clinical Pharmacokinetics, 34: 101-154. DOI: 10.2165/00003088-199834020-00002

Feng, D., R.P. Tracy, I. Lipinska, J. Murillo and C. McKenna et al., 2000. Effect of short-term aspirin use on C-reactive protein. J. Thrombosis Thrombolysis, 9: 37-41. $\quad$ DOI: 10.1023/A:1018644212794

Gomez-Flores, R., D. Caballero-Hernandez, R.J., Weber, R. Tamez-Guerra and P. Tamez-Guerra et al., 2005. In vitro activation of human and rat lymphocyte and macrophage functions by norepinephrine. Am. J. Immunol, 1: 148-153. DOI: 10.3844 /ajisp.2005.148.153

Hirose, L., K. Nosaka, M. Newton, A. Laveder and M. Kano et al., 2004. Changes in inflammatory mediators following eccentric exercise of the elbow flexors. Exercise Immunology Rev., 10: 75-90.

Kimura, H., M. Suzui, F. Nagao and K. Matsumoto, 2001. Highly sensitive determination of plasma cytokines by time-resolved fluoroimmunoassay; effect of bicycle exercise on plasma level of interleukin-1 alpha (IL-1 alpha), tumor necrosis factor alpha (TNF alpha) and interferon gamma (IFN gamma). Anal Sci., 17: 593-597. DOI: 10.2116/analsci.17.593

Lopez, C., D. Kirkpatrick, S.E. Read, P.A. Fitzgerald and J. Pitt et al., 1983. Correlation between low natural killing of fibroblasts infected with herpes simplex virus type 1 and susceptibility to herpesvirus infections. Am. J. Infect. Dis., 147: 1030-1035.

Nemet, D., C.M. Rose-Gottron, P.J. Mills and D.M. Cooper, 2003. Effect of water polo practice on cytokines, growth mediators and leukocytes in girls. Medicine Sci. Sports Exer., 35: 356-363. DOI: 10.1249/01.MSS.0000048722.84182.E3

Nemet, D., Y. Oh, H.S. Kim, M. Hill and D.M. Cooper, 2002. Effect of intense exercise on inflammatory cytokines and growth mediators in adolescent boys. Pediatrics, 110: 681-689. DOI: 10.1542/peds.110.4.681

Nieman, D.C., 1998. Exercise and resistance to infection. Canadian J. Physiol. Pharmacol., 76: 573-580. DOI: 10.1139/CJPP-76-5-573

Nieman, D.C., D.A. Henson, C.L. Dumke, K. Oley and S.R. McAnulty et al., 2006. Ibuprofen use, endotoxemia, inflammation and plasma cytokines during ultramarathon competition. Brain Behav. Immun., 20 : 578-584. $\quad$ DOI: 10.1016/j.bbi.2006.02.001 
Ostrowski, K., P. Schjerling and B.K. Pedersen, 2000. Physical activity and plasma interleukin-6 in humans-effect of intensity of exercise. Eur. J. Applied Physiol., 83:512-515. DOI: 10.1007/S004210000312

Pedersen, B.K. and H. Bruunsgaard, 1995. How physical exercise influences the establishment of infections. Sports Med., 19: 393-400.

Semark, A., T.D. Noakes, A.S.C. Gibson and M.I. Lambert, 1999. The effect of a prophylactic dose of flurbiprofen on muscle soreness and sprinting performance in trained subjects. J. Sports Sci., 17: 197-203. DOI: 10.1080/026404199366091

Shephard, R.J., S. Rhind and P.N. Shek, 1994. Exercise and the immune system. Natural killer cells, interleukins and related responses. Sports Med., 18:340-369.

Suzuki, K., S. Nakaji, M. Yamada, M. Totsuka and K. Sato et al., 2002. Systemic inflammatory response to exhaustive exercise. Cytokine kinetics. Exercise Immunology Rev., 8:6-48.
Tokmakidis, S.P., E.A. Kokkinidis, I. Smilios and H. Douda, 2003. The effects of ibuprofen on delayed muscle soreness and muscular performance after eccentric exercise. J. Strength Conditioning Research/National Strength Conditioning Assoc., 17:53-59.

Trinchieri, G., 1989. Biology of natural killer cells. Adv. Immunol., 47: 187-376. DOI: 10.1016/S0065-2776(08)60664-1

Zaldivar, F., J. Wang-Rodriguez, D. Nemet, C. Schwindt and P. Galassetti et al., 2006. Constitutive pro- and anti-inflammatory cytokine and growth factor response to exercise in leukocytes. J. Appl. Physiol., 100 : 1124-1133. $\quad$ DOI: 10.1152/japplphysiol.00562.2005 